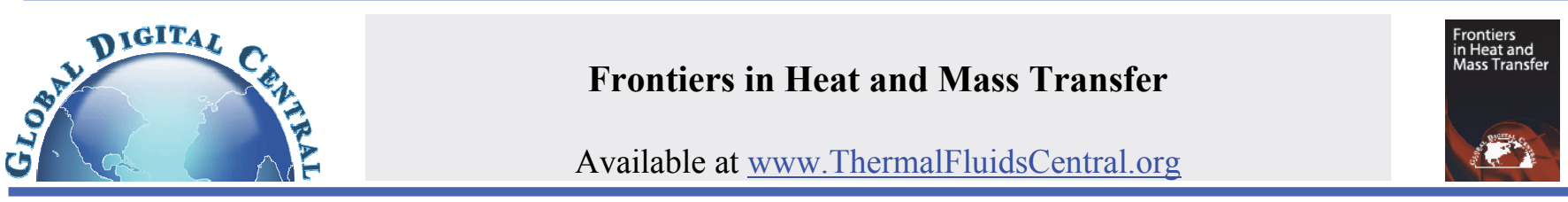

\title{
RADIATION ABSORPTION AND CHEMICAL REACTION EFFECTS ON MHD FLOW OF HEAT GENERATING CASSON FLUID PAST OSCILLATING VERTICAL POROUS PLATE
}

\author{
S. Harinath Reddy ${ }^{a}$, M.C. Raju ${ }^{a^{*}}$, E. Keshava Reddy ${ }^{b}$ \\ ${ }^{a}$ Department of Humanities and Sciences, Annamacharya Institute of Technology and Sciences Rajampet (Autonomous), Rajampet, Andhra Pradesh, \\ 516126 India \\ ${ }^{b}$ Department of Mathematics, JNTUA, Ananthapuram, 515001, Andhra Pradesh, India
}

\begin{abstract}
This manuscript presents a detailed numerical study on the influence of radiation absorption and chemical reaction on unsteady magneto hydrodynamic free convective heat and mass transfer flow. A heat generating Casson fluid past an oscillating vertical plate embedded in a porous medium in the presence of constant wall temperature and concentration is considered. The non-dimensional governing equations along with the corresponding boundary conditions are solved using Finite difference method numerically. Effects of various emerging flow parameters on concentration, temperature and velocity distributions are presented graphically and analyzed. Expressions for skin-friction, Nusselt number and Sherwood number are also obtained. Effects of radiation absorption and homogeneous chemical reaction are considered here. It is interesting to note that, the presence of the chemical reaction reduces the velocity of the Casson fluid whereas it has different impact in the presence of radiation absorption. Also increasing values of chemical reaction parameter leads to decrease the concentration of the Casson fluid.

Keywords: Casson fluid, MHD, porous medium, Heat and mass transfer, free convection, chemical reaction, Radiation absorption, heat absorption/generation.
\end{abstract}

\section{INTRODUCTION}

The study of Casson fluid flow on MHD free convection flows with heat transfer past a porous plate is attracting the attention of many researchers. This fluid has distinct features and is quite illustrious recently. Casson first coined Casson fluid model in 1959 for the prediction of the flow behavior of pigment-oil suspension. So for the flow, the shear stress magnetic of Casson fluid needs to exceed the yield shear stress, or else the fluid behaves as a rigid body. This kind of fluids can be marked as a purely viscous fluid with high viscosity. Casson model is based on a structure model of the combined behavior of solid and liquid phases of two-phase suspensions. Some famous examples of Casson fluid include jelly, sauce, tomato, honey, soup and concentrated fruit juice. Human blood can also be treated as Casson fluid due to the presence of several substances such as fibrinogen, protein, globulin in aqueous base plasma and human red blood cell. In all of the above studies, the solutions of Casson fluid are obtained either by using approximate method or by any numerical scheme. The exact analytical solutions of Casson fluid are obtained in many cases. Mernone et al. (2002) discussed a mathematical study of peristaltic transport of a Casson fluid. Chamkha et al. (2001) considered radiation effect on natural convection flow past a semi-infinite vertical plate with mass transfer. Dash et al. (1996) investigated the characteristics of Casson fluid flow in a pipe filled with a homogeneous porous medium. Gilbert et al. (2015) analyzed effect of radiation on magnetohydrodynamic free convection Casson fluid flow from a horizontal circular cylinder with partial slip and viscous dissipation in non-Darcy porous medium. Bhattacharyya et al. (2013) studied MHD stagnation point of Casson fluid flow and heat transfer along a stretching sheet in the presence of thermal radiation. Raju et al. (2015) considered Heat and mass transfer in magnetohydrodynamic Casson fluid over an exponentially permeable stretching surface. Boyd et al. (2007) discussed analysis of the Casson and Carreau-Yasuda nonNewtonian blood models in the steady and oscillatory flows using the lattice Boltzmann method. Pramanic et al. (2014) investigated on Casson fluid flow and heat transfer past an exponentially permeable stretching surface in presence of thermal radiation. Kirubhashankar et al. (2015) presented Casson Fluid Flow and Heat Transfer over an unsteady porous stretching surface. Hayat et al. (2012) analyzed the Soret and Dufour effects on MHD flow of Casson fluid. Hussanan et al. (2014) studied Unsteady boundary layer flow and heat transfer of a Casson fluid past an oscillating vertical plate with Newtonian heating. Bhattacharyya et al.(2013a) considered Exact solution for boundary layer flow of Casson fluid over a permeable stretching/shrinking sheet. Ganesan et al. (2002) investigated radiation and mass transfer effects of incompressible viscous fluid flow past a moving cylinder. Nadeem et al. (2003) analyzed MHD three-dimensional Casson fluid flow past a porous linearly stretching sheet. Swathi Mukhopadhyay et al. (2013) investigated Casson fluid flow and heat transfer over a non-linear stretching surface. Kalid et al. (2015) considered unsteady MHD free convection flow of Casson fluid past over an oscillating vertical plate embedded in porous medium. Hari et al. (2016) studied Soret and heat generation effects on MHD Casson Fluid flow past an oscillating vertical plate embedded through porous medium. Abiodun et al.(2015) investigated effect of Chemical Reaction and Radiation Absorption on The Unsteady MHD Free Convection Couette Flow in a Vertical Channel Filled With Porous Materials. Seethamahalakshmi et al. (2011) considered Effects of The Chemical Reaction and Radiation Absorption on an Unsteady MHD Convective Heat and Mass Transfer Flow Past a Semi-Infinite Vertical Moving in a Porous Medium With Heat Source and Suction. Seyed et al. (2014) investigated Analysis of Forced Convection in a Circular Tube Filled With a Darcy-BrinkmanForchheimer Porous Medium Using Spectral Homotopy Analysis 
Method. Seyed et al. (2011) analyzed Analysis of Forced Convection in a Circular Tube Filled With a Darcy-Brinkman-Forchheimer Porous Medium Using Spectral Homotopy Analysis Method. Hamid et al. (2011) studied An Analytical Study for Fluid Flow in Porous Media Imbedded Inside a Channel with Moving or Stationary Walls Subjected to Injection/Suction. Sayed et al. (2013 ) investigated Heat Transfer Through a Porous Saturated Channel With Permeable Walls Using Two-Equation Energy Mode. Seyed et al. (2014) considered Analytical Flow Study of a Conducting Maxwell Fluid Through a Porous Saturated Channel at Various Wall Boundary Conditions.

Keeping in mind the work done by previous researchers, we attempted to analyze radiation absorption and chemical reaction effects on unsteady magneto hydrodynamic free convective heat and mass transfer flow of a heat absorbing/generating Casson fluid past an oscillating vertical plate embedded in a porous medium in the presence of constant wall temperature and concentration. The novelty of this work is the consideration of radiation absorption, heat source/sink and chemical reaction in conservation of energy and mass diffusion equations respectively. We have extended the work of Khalid et al. (2015) by including the presence of above mentioned flow parameters. This is not a simple extension of the previous work; it varies several aspects from that such as the presence of mass transfer in the momentum equation, radiation absorption inclusion in the energy equation and the addition of species diffusion equation. Apart from the modification of set of governing equations, we also changed the method of solution due to the existence of nonlinear-coupled partial differential equations, which are solved, by finite difference method instead of Laplace transform technique.

\section{FORMULATION OF THE PROBLEM:}

Influence of radiation absorption and homogeneous chemical reaction on unsteady MHD free convection heat and mass transfer flow of heat absorbing/generating Casson fluid past a semi-infinite oscillating vertical plate embedded in uniform porous medium with constant wall temperature and concentration is considered. Let $\mathrm{x}$ - axis taken towards upward direction along with the fluid and y-axis is taken normal to it. The fluid assumed hear is an electrically conducting with a uniform magnetic field of strength $\mathrm{B}_{0}$ is applied in a direction perpendicular to the plate. The magnetic Reynolds's number is assumed very small so that it may be ignored in comparison with magnetic field. Initially at $\mathrm{t}=0$, the fluid is assumed to be at rest and the plate and fluid are maintained at uniform temperature and concentration. For $t>0$, the plate begins to oscillate in its own plane $(y=0)$ in the form

$V=U H(t) \cos (w t) i$ or $V=U \sin (w t) i$

where $H(t)$ is the unit step function, constant $\mathrm{U}$ is the amplitude of the plate oscillations, $\mathbf{i}$ is the unit vector in the vertical flow direction and $\omega$

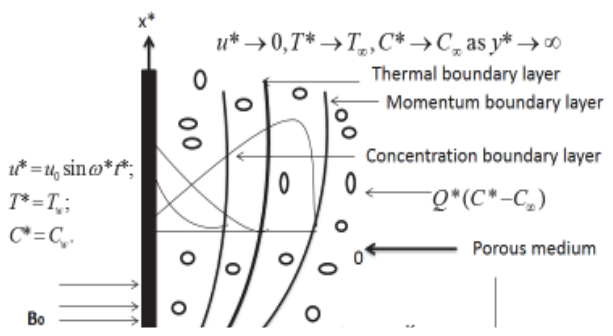

Fig.1 Physical model and coordinate system is the frequency of oscillation of the plate. At the same time, the plate temperature is raised to $T_{w}$ which is thereafter maintained constant.

The tensor of the Casson fluid can be written as $\tau=\tau_{0}+\mu \gamma^{*}$ or

$\tau_{i j}=\left\{\begin{array}{l}2\left(\mu_{B}+\frac{P y}{\sqrt{2 \pi}}\right) e_{i j}, \pi>\pi_{c} \\ 2\left(\mu_{B}+\frac{P y}{\sqrt{2 \pi}}\right) e i j, \pi<\pi_{c}\end{array}\right.$

Where $\pi=e_{i j} e_{i j}$ and $e_{i j}$ is the $(i, j)^{\text {th }}$ component of deformation rate, $\pi$ is the product of the component of deformation rate with itself, $\pi_{\mathrm{c}}$ is the critical value of this product based on the non-Newtonian fluid, $\mu_{\mathrm{B}}$ is the plastic dynamic viscosity of its fluid and $P y$ s yield stress of the non-Newtonian fluid. Before forming the governing equations, we have taken some assumptions that are unidirectional flow, one dimensional flow, free convection, rigid plate, incompressible flow, unsteady flow, non-Newtonian flow, oscillating vertical plate and viscous dissipation term in the energy equation is neglected. Considering the above assumptions, we have formed the following set of partial differential equations.

$$
\begin{aligned}
& \rho \frac{\partial u^{*}}{\partial t^{*}}=\mu_{\beta}\left(1+\frac{1}{\gamma}\right) \frac{\partial^{2} u^{*}}{\partial y^{*}}-\sigma B_{0}^{2} u^{*}-\frac{\mu \phi}{k_{1}} u^{*} \\
& +\rho g \beta\left(T^{*}-T_{\infty}\right)+\rho g \beta^{*}\left(C^{*}-C_{\infty}\right) \\
& \rho C_{p} \frac{\partial T^{*}}{\partial t^{*}}=k \frac{\partial^{2} T^{*}}{\partial y^{*}}+Q\left(T^{*}-T_{\infty}\right)+\mu\left(\frac{\partial u^{*}}{\partial y^{*}}\right)^{2}+Q^{*}\left(C^{*}-C_{\infty}\right)
\end{aligned}
$$

$\frac{\partial C^{*}}{\partial t^{*}}=D \frac{\partial^{2} C^{*}}{\partial y^{* 2}}-K r\left(C-C_{\infty}\right)$

The initial and boundary conditions are

$$
\left.\begin{array}{l}
t^{*}<0: u^{*}=0, T^{*}=T_{\infty}, C^{*}=C_{\infty} \quad \text { forall } y^{*}<0 \\
t^{*} \geq 0: u^{*}=u_{0} \sin \left(w^{*} t^{*}\right), T^{*}=T_{w}, \mathrm{C}^{*}=C_{w} \text { at } y^{*}=0 \\
u^{*} \rightarrow 0, T^{*} \rightarrow T_{\infty}, C^{*} \rightarrow C_{\infty} \text { as } y^{*} \rightarrow \infty
\end{array}\right\}
$$

Here $u$-the velocity of the fluid along x-direction, $\rho$ - the constant density, $\mu_{\beta}$-plastic dynamic viscosity, $k$-permeability of the fluid, $\mathrm{C}$ concentration, $\mathrm{T}$-temperature, $\mathrm{C}_{\mathrm{p}}$-specific heat at constant Casson parameter, $\sigma$-electric conductivity of the fluid, $\beta$-volumetric coefficient of thermal expansion, $\phi$-porosity parameter, $t$-the time factor, $Q$-dimensional heat source/sink, $Q^{*}$-dimensional radiation absorption parameter.

On introducing the following non-dimensional variables and parameters

$$
\begin{aligned}
& u=\frac{u^{*}}{u_{0}}, t=\frac{t^{*} u_{0}^{2}}{v}, \mathrm{y}=\frac{y^{*} u_{0}}{v}, \theta=\frac{T^{*}-T_{\infty}}{T_{w}-T_{\infty}}, \mathrm{C}=\frac{C^{*}-C_{\infty}}{C_{w}-C_{\infty}}, \\
& \tau^{*}=\frac{\tau}{\rho u_{0}^{2}} \omega^{*}=\frac{\omega v}{u_{0}^{2}} .
\end{aligned}
$$


into the set of equations (1)-(3), these equations reduce to the following set of dimensionless equations:

$$
\begin{aligned}
& \frac{\partial u}{\partial t}=\left(1+\frac{1}{\gamma}\right) \frac{\partial^{2} u}{\partial y^{2}}-M u-\frac{1}{k} u+G r \theta+G m C \\
& \frac{\partial \theta}{\partial t}=\frac{1}{\operatorname{Pr}} \frac{\partial^{2} \theta}{\partial y^{2}}+\Gamma \theta+E c\left(\frac{\partial u}{\partial y}\right)^{2}+R C \\
& \frac{\partial C}{\partial t}=\frac{1}{S c} \frac{\partial^{2} C}{\partial y^{2}}-K r C
\end{aligned}
$$

The corresponding initial and boundary conditions are:

$$
\left.\begin{array}{rlrl}
t<0: u & =0, \theta=0, C=0 & & \text { for all } y<0 \\
t \geq 0: u & =\sin (w t), \theta=1, C=1 & & \text { at } y=0 \\
u & \rightarrow 0, \theta \rightarrow 0, C \rightarrow 0 & \text { as } y \rightarrow \infty
\end{array}\right\}
$$

Where $G r=\frac{\operatorname{vg} \beta\left(T_{w}-T_{\infty}\right)}{u_{0}^{3}}$ is the Grashof number;

$\gamma=\frac{\mu_{B} \sqrt{2 \pi c}}{P y} \quad$ is the Casson parameter;

$\Gamma=\frac{Q v}{\rho C_{p} u_{0}^{2}}$ is the heat generation parameter;

$M=\frac{\sigma B_{0}^{2} v}{\rho u_{0}^{2}}$ is the magnetic parameter;

$K=\frac{k_{1} u_{0}^{2}}{\phi v^{2}}$ is the permeability parameter;

$G m=\frac{v g \beta^{*}\left(C_{w}-C_{\infty}\right)}{u_{0}^{3}}$ is the modified Grashof number;

$\operatorname{Pr}=\frac{v \rho C_{p}}{k}$ is the Prandtl number;

$R=\frac{\left(C_{w}-C_{\infty}\right) Q^{*} v}{\left(T_{w}-T_{\infty}\right) \rho C p u_{0}^{2}}$ is the radiation absorption parameter;

$S_{c}=\frac{v}{D}$ is the Schmidt number;

$K r=\frac{K r^{*} v}{u_{0}^{2}}$ is the chemical reaction parameter;

$E c=\frac{u_{0}^{2}}{C p\left(T_{w}-T_{\infty}\right)}$ is the Eckert number.

\section{METHOD OF SOLUTION}

Equations (6)-(8) are linear partial differential equations and are to be solved by using the initial and boundary conditions (9). However exact solution is not possible for this set of equations and hence we solve these equations by finite-difference method. The equivalent finite difference schemes of equations for (6)-(8) are as follows:

$$
\begin{aligned}
& \frac{u_{i, j+1}-u_{i, j}}{\Delta t}=\left(1+\frac{1}{\gamma}\right)\left(\frac{u_{i-1, j}-2 u_{i, j}+u_{i+1, j}}{(\Delta y)^{2}}\right)-M u_{i, j} \\
& -\frac{1}{K} u_{i, j}+G r \theta_{i, j}+G m C_{i, j} \\
& \begin{aligned}
\frac{\theta_{i, j+1}-\theta_{i, j}}{\Delta t}= & \frac{1}{\operatorname{Pr}}\left(\frac{\theta_{i-1, j}-2 \theta_{i, j}+\theta_{i+1, j}}{(\Delta y)^{2}}\right) \\
\frac{C_{i, j+1}-C_{i, j}}{\Delta t}= & \frac{1}{S c}\left(\frac{C_{i-1, j}-2 C_{i, j}+C_{i+1, j}}{(\Delta y)^{2}}\right)-K r C_{i, j}
\end{aligned}
\end{aligned}
$$

Here, index $\mathrm{i}$ refer to $\mathrm{y}$ and $\mathrm{j}$ to time. The mesh system is divided by taking $\Delta y=0.12$. From the initial condition in (9), we have the following equivalent:

$$
u(i, 0)=0, \theta(i, 0)=0, C(i, 0)=0 \text { for all } i
$$

The boundary conditions from (8) are expressed in finite-difference form as follows

$u(0, j)=1, \theta(0, j)=1, C(0, j)=1$ for all $j$

$u\left(i_{\max }, j\right)=\sin \left(w^{*}(j-1) * \Delta t\right), \theta\left(i_{\max }, j\right)=1, C\left(i_{\max }, j\right)=1$ for all $j$

(Here $\mathrm{i}_{\max }$ was taken as 201)

First the velocity at the end of time step viz, $u(i, j+1), i=1,201)$ is computed from eqn. (10) in terms of velocity, temperature and concentration at points on the earlier time-step. Then $\theta(i, j+1)$ is computed from eqn. (11) and $\mathrm{C}(\mathrm{i}, \mathrm{j}+1)$ is computed from eqn. (12). The procedure is repeated until $\mathrm{t}=0.03$ (i.e. $\mathrm{j}=300$ ). During computation, $\Delta \mathrm{t}$ was chosen as 0.001 .

\section{Skin-friction:}

The skin-friction in non-dimensional form is given by

$$
\tau=-\left(1+\frac{1}{\gamma}\right)\left(\frac{\partial u}{\partial y}\right)_{y=0}, \text { where } \tau^{*}=\frac{\tau}{\rho u_{0}^{2}}
$$

Rate of heat transfer:

The dimensionless rate of heat transfer is given by

$$
N u=-\left(\frac{\partial \theta}{\partial y}\right)_{y=0}
$$

Rate of mass transfer:

The dimensionless rate of mass transfer is given by

$$
S h=-\left(\frac{\partial C}{\partial y}\right)_{y=0}
$$

\section{RESULT AND DISCUSSION:}

A numerical study has been carried out to examine the characteristics of various parameters on MHD flow of a Casson fluid. The effects of different physical parameters like Grashof number(Gr), modified Grashof number(Gm), radiation absorption (R), Casson parameter $(\gamma)$, 
magnetic parameter(M), chemical reaction $(\mathrm{Kr})$, permeability parameter $(\mathrm{K})$, Prandtl number( $\mathrm{Pr})$, heat source or sink $(\Gamma)$, Schmidt number $(\mathrm{Sc})$ on concentration, temperature and velocity are analyzed with the help of graphs.

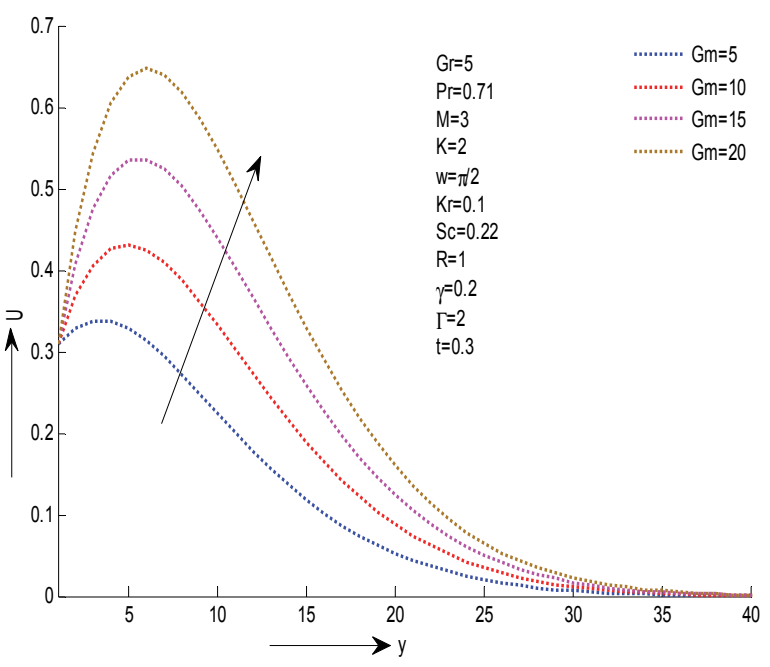

Fig. 2 Effect of Gm on velocity

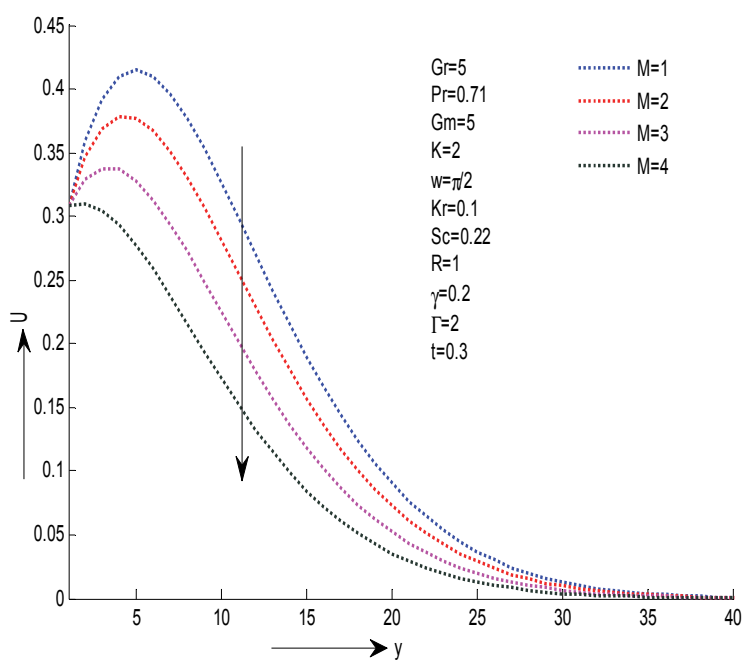

Fig. 3 Effect of $M$ on velocity

Figure 2 exhibits the effect of modified Grashof number on velocity. From this figure, it is noticed that the velocity of the fluid increases as $\mathrm{Gm}$ increases. This is due to larger buoyancy force caused by the concentration difference near the plate. The modified Grashof number $\mathrm{Gm}>0$ indicates that the chemical species concentration in the free stream region is less than the concentration at the boundary surface. The cooling problem is often encountered in engineering applications.

From Fig.3, it is noticed that the velocity profile decreases with an increment in the magnetic parameter. It is because that the application of transverse magnetic field will result a resistive type force (Lorentz force) similar to drag force which tends to resist the fluid flow and thus reducing its velocity. In addition, the boundary layer thickness decreases with an increase in magnetic parameter. Umamaheswar et al. (2015) note similar observations. The velocity profile for different values of chemical reaction parameter is shown in Fig.4. From this figure, it is observed that the velocity of the Casson fluid decreases when chemical reaction parameter increases. Fig.5 exhibits the effect of thermal Grashof number on velocity. From this figure, it is evident that the velocity profile increases when Grashof number increases. Therefore, an increase in the values of Gr leads to increase in buoyancy forces, consequently velocity increases. Here the thermal Grashof number represents the effect of free convection currents. Physically, Gr $>0$ means heating of the fluid of cooling of the boundary surface, $\mathrm{Gr}<$ 0 means cooling of the fluid of heating of the boundary surface and $\mathrm{Gr}$ $=0$ corresponds the absence of free convection current. Fig. 6 depicts the effect of $\operatorname{Pr}$ on velocity. It is noticed that velocity of the fluid decreases as Pr increases. Fig.7 demonstrates that the velocity of Casson fluid increases with an increase in radiation absorption parameter. Velocity is observed to increase with the increasing values of radiation absorption parameter. Umamaheswar et al. (2015 \& 2016) observe similar results. From fig. 8 indicates that the velocity profile increases with an increment in permeability parameter $\mathrm{K}$. The effect of heat source and sink on the velocity profiles is presented in the Fig.9. It is noticed that the velocity increases with increasing values of $\Gamma$ and decreases for decreasing values of $\Gamma$. From Fig.10, it is noticed that the velocity of the fluid decreases with an increase in Casson fluid parameter $\gamma$. Due to the increase of Casson parameter, the yield stress py falls and consequently, velocity boundary layer thickness decreases. The influence of angular velocity (w) on the velocity profiles is shown in Fig.11. It is noticed that velocity increases with increasing values of w. From Fig.12, it can be observed that the temperature increases when $\mathrm{R}$ increases. From Fig. 13 it is seen that the temperature of the Casson fluid decreases when Pr increases. Moreover, the thermal boundary layer thickness decreases by increasing Prandtl numbers. Wall temperature gradient is negative for all values of Prandtl number, which means that the heat is always transferred from the surface to the ambient fluid. An increase in Prandtl number reduces the thermal Boundary layer thickness. Prandtl number signifies the ratio of momentum diffusivity to thermal diffusivity. Fluids with lower Prandtl number will possess higher thermal conductivities (And thicker thermal boundary layer structures), so that heat can diffuse from the sheet faster than for higher Pr fluids (thinner boundary layers).

Fig. 14 depicts the variations in temperature profile for different values of $\Gamma$. It is noticed that temperature increases as $\Gamma$ increases. Fig. 15 indicates that, concentration profile decreases with an increase in $\mathrm{Kr}$. An increase in chemical reaction parameter will suppress the concentration of the fluid. Higher values of $\mathrm{Kr}$ amount to a fall in the chemical molecular diffusivity, i.e., less diffusion. Therefore, species transfer obtains them. An increase in $\mathrm{Kr}$ will suppress species concentration. The concentration distribution decreases at all points of the flow field with the increase in the reaction parameter. From Fig. 16, it is identified that as the Schmidt number, $S c$ increases the concentration decreases. This causes the concentration buoyancy effects to decrease yielding a reduction in the fluid velocity. The reductions in the velocity and concentration profiles are accompanied by simultaneous reductions in the velocity and concentration boundary layers. Effect of Eckert number on temperature is presented in Fig. 17. From the figure, it is noticed that temperature of the fluid slightly increased with the increase in Eckert number. Also the variations in Sherwood number, Nusselt number and skin friction under the influence of some important parameters are studied with the help of recorded tabular values. From Table. 1 it is observed that skin friction increases with an increase in Sc and Pr, while it decreases with an increase in Gr. From Table. 2 we have seen that the Nusselt number decreases with increasing values of source or sink and radiation absorption parameter, whereas Nusselt number increases for rising values of Pr. It is observed from Table.3 that Sherwood number enhances for increasing values of both Schmidt number and chemical reaction parameter. 


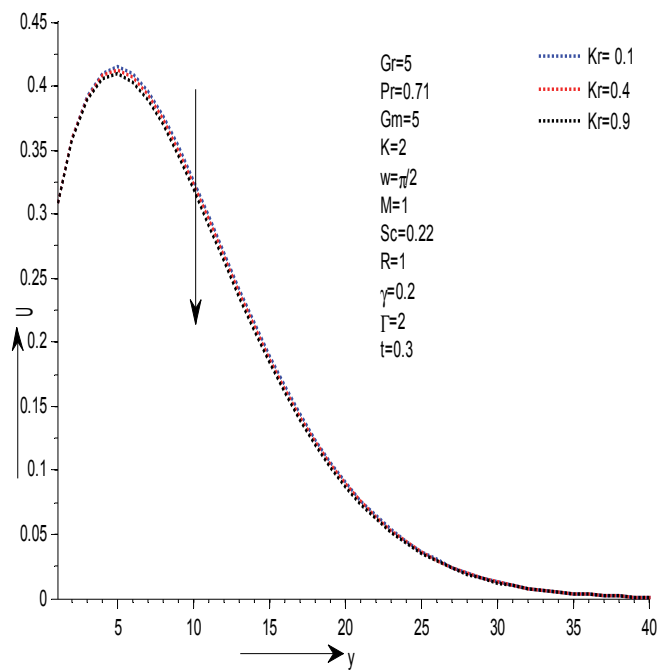

Fig. 4 Effect of $\mathrm{Kr}$ on velocity

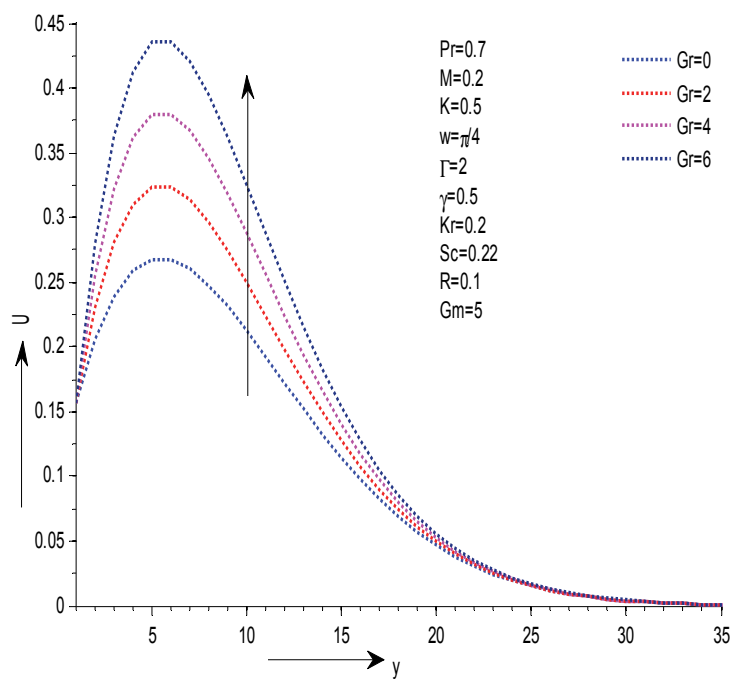

Fig. 5 : Effect of Gr on velocity

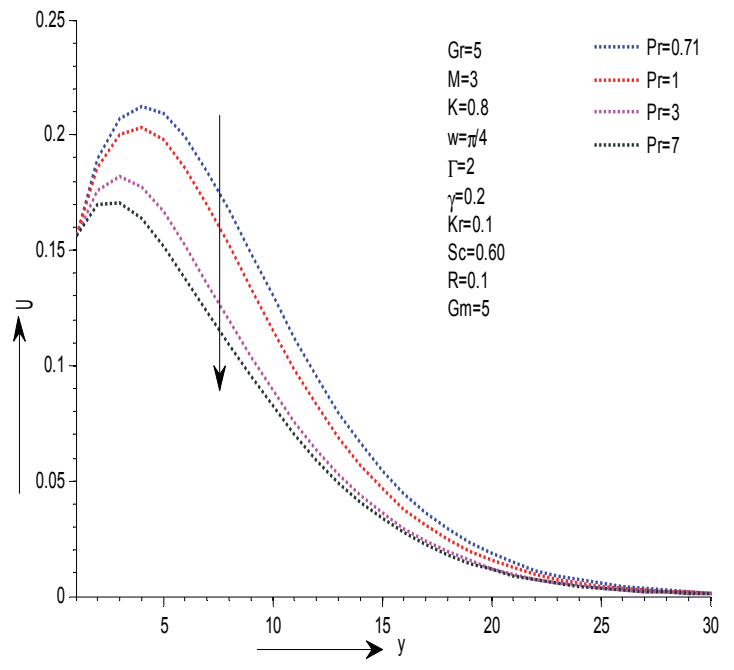

Fig. 6 Effect of Prandtl number (Pr) on Velocity.

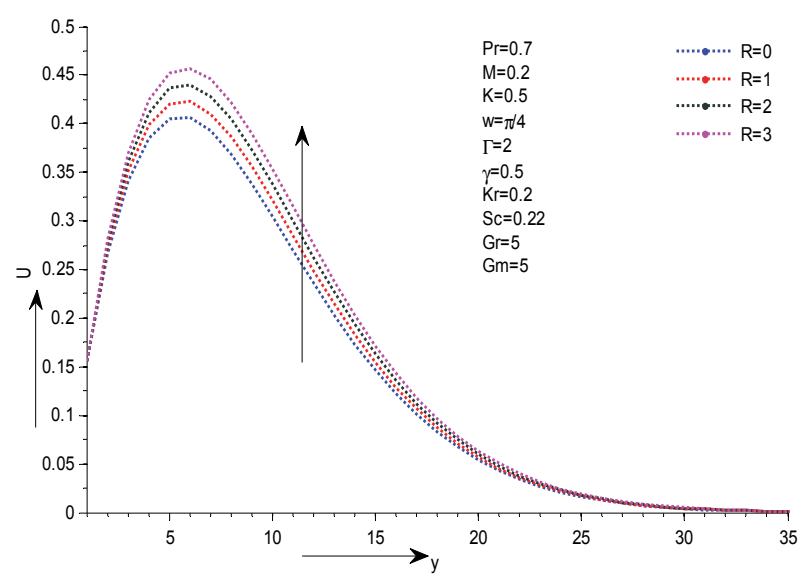

Fig. 7 Effect of $R$ on velocity

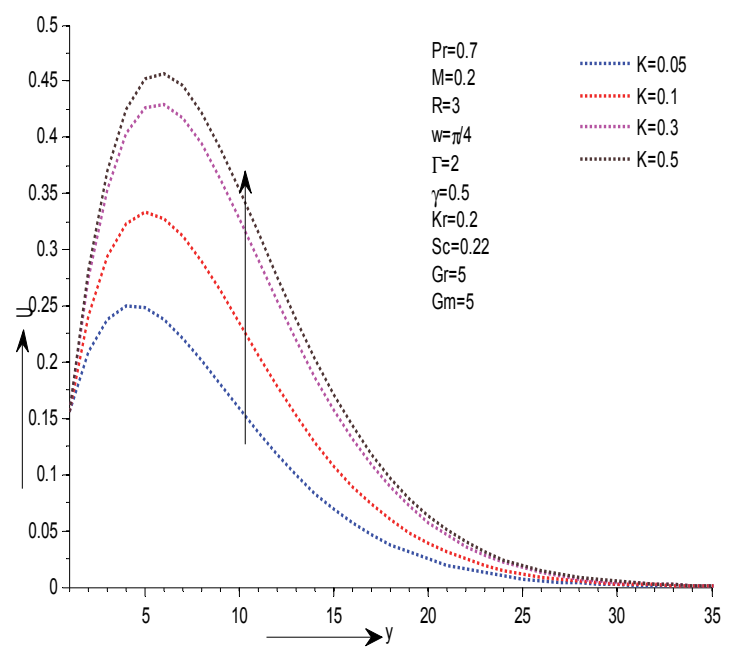

Fig. 8 : Effect of K on velocity

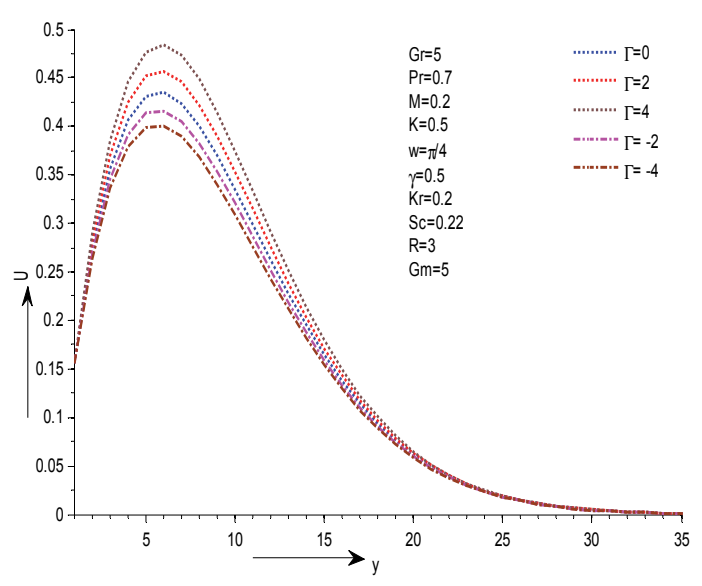

Fig. 9 Effect of source and sink on velocity 


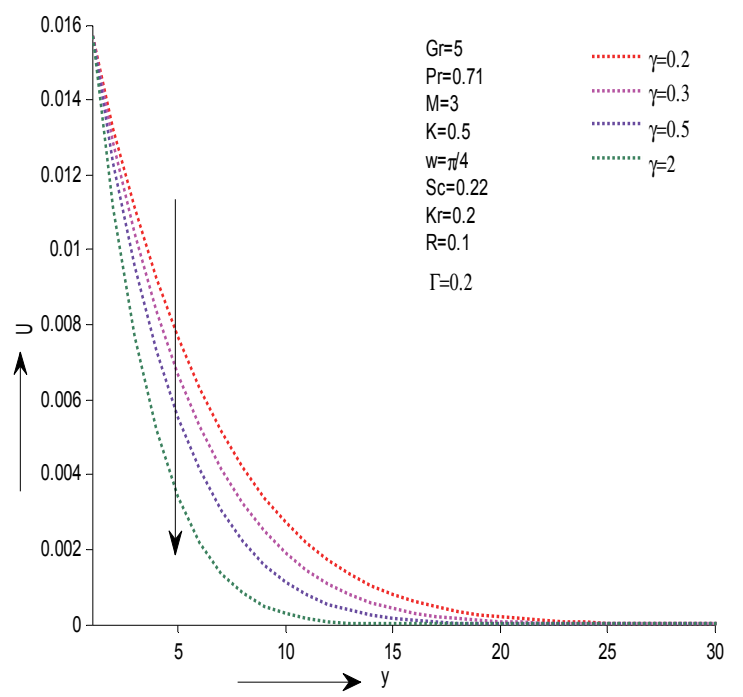

Fig. 10 Effect of Casson parameter on velocity

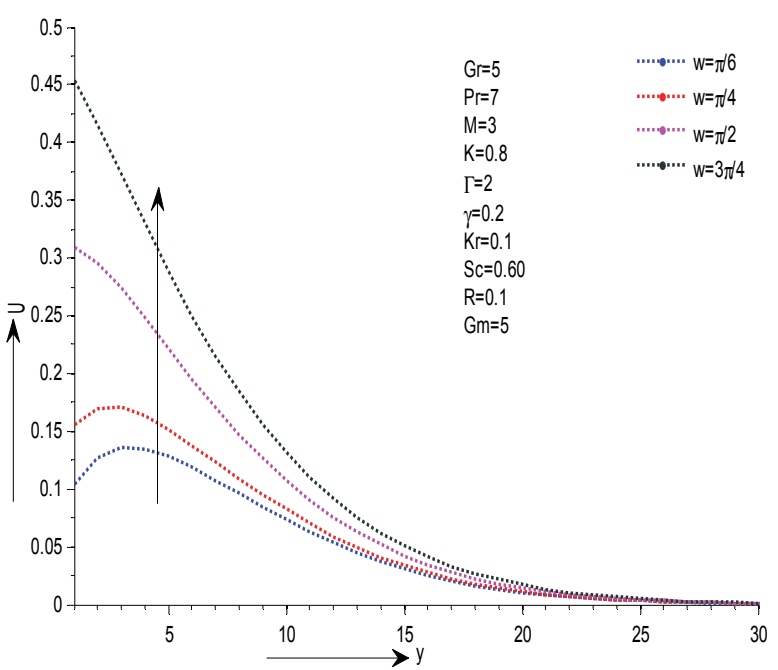

Fig. 11 Effect of W on velocity

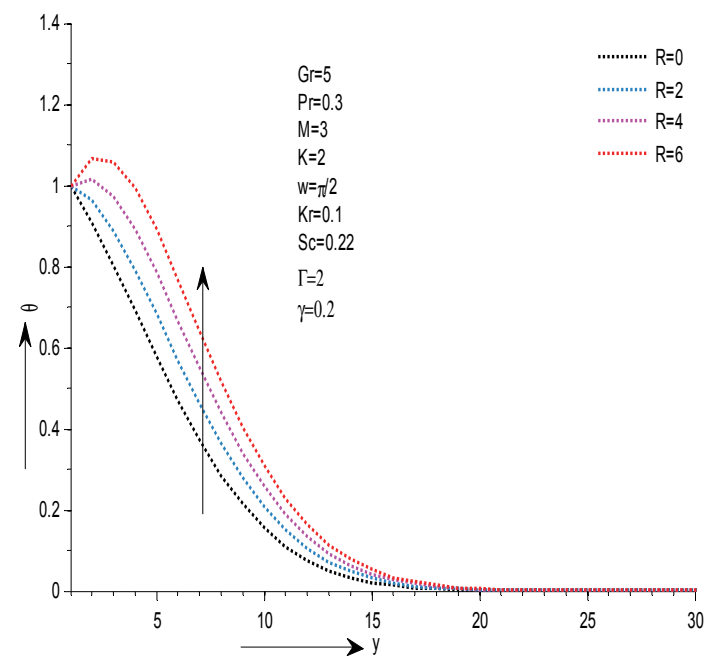

Fig. 12 Effect of radiation absorption on Temperature

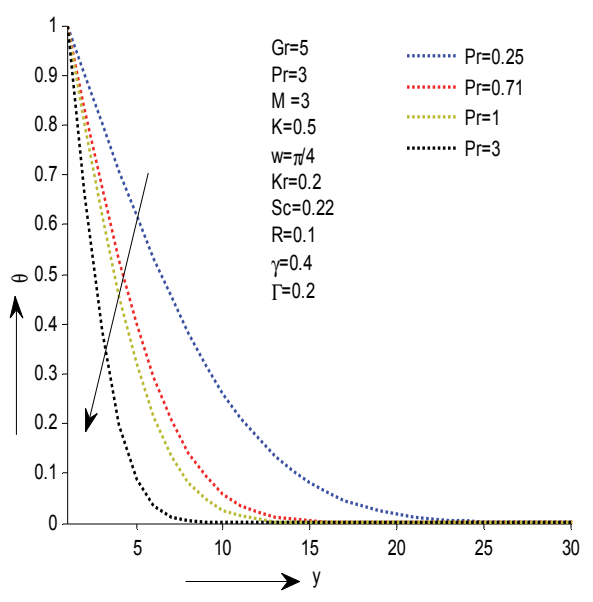

Fig. 13 Effect of Pr on Temperature

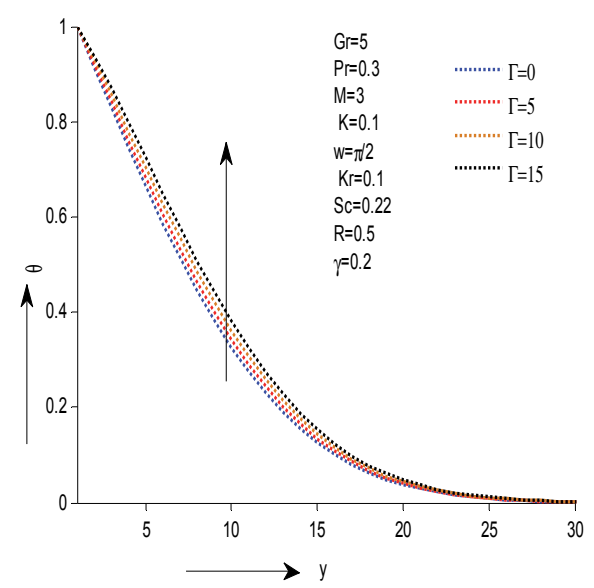

Fig. 14 Effect of heat generation parameter on Temperature.

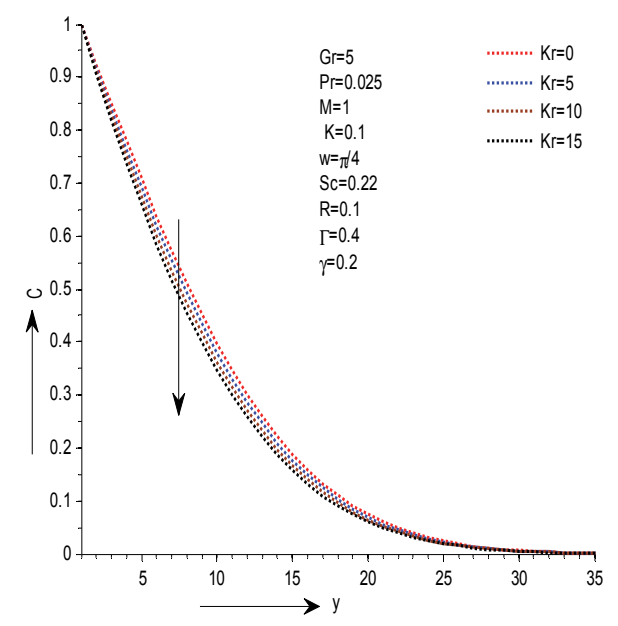

Fig. 15. Effect of $\mathrm{Kr}$ on concentration 
Table.3: Sherwood number variations

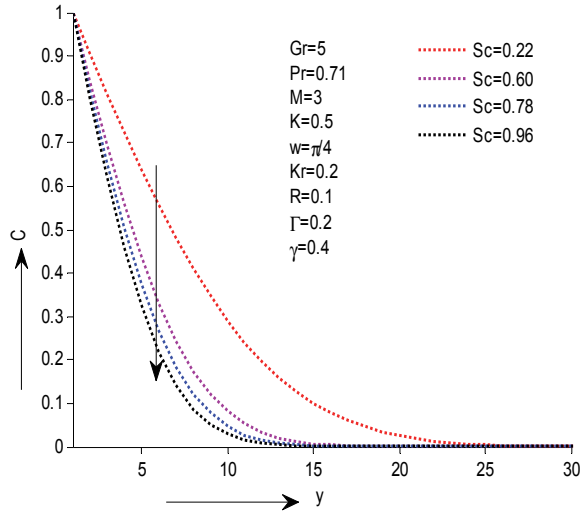

Fig. 16 Effect on Sc on concentration.

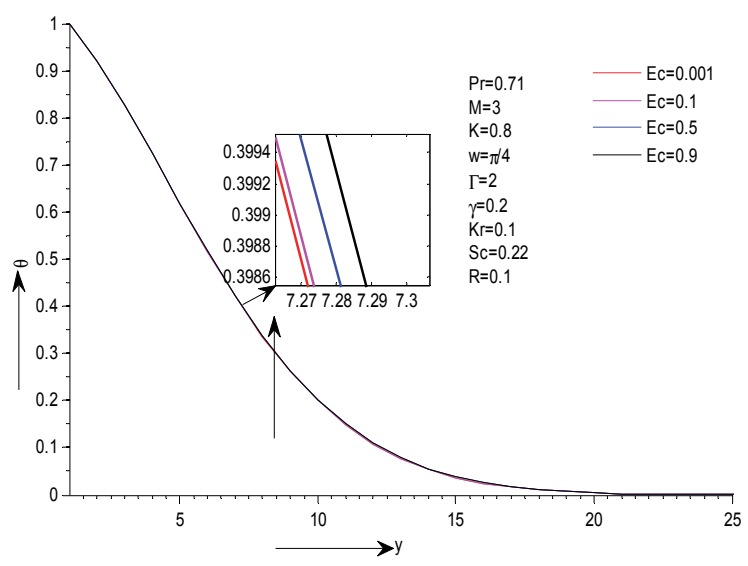

Fig. 17 Effect of Eckert number on Temperature

Table.1: Skin-friction variations

\begin{tabular}{|c|c|c|}
\hline Kr & Sc & Sh \\
\hline 0.8 & 0.22 & 5.4593 \\
\hline 0.8 & 0.60 & 10.8761 \\
\hline 0.8 & 0.78 & 12.1547 \\
\hline 0.1 & 0.78 & 12.1526 \\
\hline 0.3 & 0.78 & 12.1532 \\
\hline 0.5 & 0.78 & 12.1544 \\
\hline
\end{tabular}

Table.2: Nusselt number variations

\begin{tabular}{|l|l|l|l|}
\hline $\operatorname{Pr}$ & $\Gamma$ & $\mathrm{R}$ & $\mathrm{Nu}$ \\
\hline 0.7 & 0.8 & 0.1 & 11.7034 \\
\hline 1 & 0.8 & 0.1 & 13.1632 \\
\hline 7 & 0.8 & 0.1 & 16.7155 \\
\hline .7 & 0.1 & 0.1 & 11.7161 \\
\hline .7 & 0.3 & 0.1 & 11.7154 \\
\hline .7 & 0.5 & 0.1 & 11.7148 \\
\hline .7 & 0.8 & 0.1 & 11.7138 \\
\hline .7 & 0.8 & 0.3 & 11.7117 \\
\hline .7 & 0.8 & 0.5 & 11.7090 \\
\hline
\end{tabular}

\begin{tabular}{|l|l|l|l|}
\hline $\mathrm{Gr}$ & $\mathrm{Pr}$ & $\mathrm{Sc}$ & 工 \\
\hline 5 & .7 & 0.78 & .0241 \\
\hline 10 & .7 & 0.78 & .0092 \\
\hline 15 & .7 & 0.78 & -.0204 \\
\hline 5 & 0.71 & 0.78 & .0243 \\
\hline 5 & 1 & 0.78 & .0290 \\
\hline 5 & 7.1 & 0.78 & .0390 \\
\hline 5 & 0.71 & 0.22 & -.0412 \\
\hline 5 & 0.71 & 0.60 & -.0079 \\
\hline 5 & 0.71 & 0.78 & -.0034 \\
\hline
\end{tabular}

In order to check the validity of our FDM solution, the dimensionless temperature profile in different values of the influential parameters is compared in absence of Sc, Kr, R, and Ec with those reported by Khalid et al. (2015). As seen in the Fig. 18 the results of the two works are in complete agreement with each other.

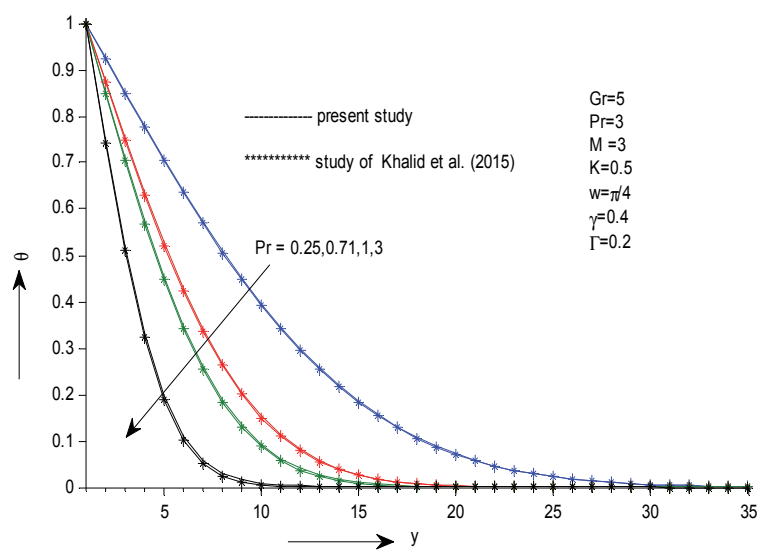

Fig. 18 Comparison of the present results with that obtained by Khalid et al. (2015) when $\mathrm{R}=0, \mathrm{Sc}=0, \mathrm{Kr}=0$

\section{CONCLUSION:}

In this manuscript, a numerical analysis is carried out to investigate the radiation absorption and chemical reaction effects on MHD heat and mass transfer flow of a Casson fluid past a oscillating vertical porous plate with heat absorption and generation. The nondimensional governing equations are solved with the help of finite difference method. The results for concentration, temperature and velocity profile are obtained and plotted graphically. The effects of Sherwood number, Nusselt number and skin-friction values are also presented in tables. The following are the conclusions of this manuscript.

1. Velocity of the Casson fluid decreases with increasing values of $\mathrm{M}, \mathrm{Kr}, \mathrm{Pr}, \gamma$ whereas it increases with increasing values of Gr, Gm, R, K, w, $\Gamma$. Also velocity of the fluid decreases with decreasing value of $\Gamma$.

2. Temperature of the Casson fluid increases with increasing values of $\mathrm{R}, \Gamma$ whereas reverse trend is seen in the case of Pr.

3. Increasing values of $\mathrm{Kr}$ and $\mathrm{Sc}$ leads to decrease the concentration of the Casson fluid.

4. Skin-friction decreases with increasing value of $\mathrm{Gr}$, and it shows reverse effect when $\mathrm{Pr}$ and Sc increases. 
5. Nusselt number decreases for rising values of $R, \Gamma$ and decreasing values of Pr.

6. Sherwood number enhances with increasing values of Sc and $\mathrm{Kr}$.

\section{REFERENCES}

Mernone, A. V., Mazumdar, J. N., and Lucas, S. K., 2002, "A Mathematical Study of Peristaltic Transport Of A Casson Fluid," Mathematical and Computer Modelling, vol. 35, no. 7-8, pp. 895-912. http://dx.doi.org/10.1016/S0895-7177(02)00058-4

Chamkha, A. J, Takhar H. S, Soundalgekar V. M., 2001, "Radiation Effects on Free-Convection Flow Past a Semi Infinite Vertical Plate With Mass Transfer," Chem. Eng. Journal.84:335-342. http://dx.doi.org/10.1016/S1385-8947(00)00378-8

Dash, R. K., Mehta, K. N., and Jayaraman, G., 1996, "Casson Fluid Flow in a Pipe Filled With a Homogeneous Porous Medium," International Journal of Engineering Science, 34(10), 1145-1156. http://dx.doi.org/10.1016/0020-7225(96)00012-2

Gilbert, M., Sachin, S., and Sibanda, P., 2015, "Effects of Radiation on MHD Free Convection of a Casson Fluid from a Horizontal Circular Cylinder With Partial Slip in Non-Darcy Porous Medium With Viscous Dissipation," Boundary Value Problems, 75, 1-14.

http://dx.doi.org/10.1186/s13661-015-0333-5

Krishnendu, B., 2013), "MHD Stagnation-Point Flow of Casson Fluid and Heat Transfer over a Stretching Sheet with Thermal Radiation," Journal of Thermodynamics, Vol. 2013, ArticleID-169674.

http://dx.doi.org/10.1155/2013/169674

Raju, C. S. K., Sandeep, N., 2015), "Heat and Mass Transfer in Magnetohydrodynamic Casson Fluid Over an Exponentially Permeable Stretching Surface" Engineering Science and Technology, an International Journal, 19(1), 45-52.

http://dx.doi.org/10.1016/j.jestch.2015.05.010

Boyd, J., Buick, J. M., and Green, S., 2007), "Analysis of the Casson and Carreau-Yasuda non-Newtonian Blood Models in Steady and Oscillatory Flows using the Lattice Boltzmann method," Physics of Fluids, vol. 19, no. 9, Article ID 093103

http://dx.doi.org/10.1063/1.2772250

Pramanik, S., 2014), "Casson Fluid Flow and Heat Transfer Past an Exponentially Porous Stretching Surface in Presence of Thermal Radiation," Ain Shams Engineering Journal, 5(1), 205- 212.

http://dx.doi.org/10.1016/j.asej.2013.05.003

Kirubhashankar, C. K., Ganesh, S., 2015, "Casson Fluid Flow and Heat Transfer over an Unsteady Porous Stretching Surface," Applied Mathematical Sciences, 9(7). 345 - 351.

http://dx.doi.org/10.12988/ams.2015.411988

Hayat, T., Shehzad, S. A., 2012, "Soret and Dufour Effects on Magnetohydrodynamic (MHD) Flow of Casson Fluid," Appl. Math. Mech. -Engl. Ed., 33(10), 1301-1312.

http://dx.doi.org/10.1007/s10483-012-1623

Hussanan, M. Z., Salleh, R.M., Tahar, I. K., 2014, "Unsteady Boundary Layer Flow and Heat Transfer of a Casson Fluid Past an Oscillating Vertical Plate With Newtonian Heating," PLOS ONE e108763. http://dx.doi.org/10.1371/journal.pone.0108763
Bhattacharyya K, Hayat T and Alsaedi, A., 2013a, "Exact Solution for Boundary Layer Flow of Casson Fluid over a Permeable Stretching/Shrinking Sheet," ZAMM Z. Angew. Math. Mech. 1-7 http://dx.doi.org/10.1002/zamm.201200031P.

Ganesan and Loganadan, P, 2002, "Radiation and Mass Transfer Effects on Flow of an Incompressible Viscous Fluid Past a Moving Cylinder," Int. J. Heat and Mass Transfer, 45, 4281 - 4288.

http://dx.doi.org/10.1016/S0017-9310(02)00140-0.

Nadeem, S., Haq, R.U., Akbar, N.S., and Khan Z.H., 2013, "MHD Three-Dimensional Casson Fluid Flow Past a Porous Linearly Stretching Sheet," Alexandria Engineering Journal, 52, 577-582. http://dx.doi.org/10.1016/i.aej.2013.08.005

Swati Mukhopadhyay,(2013, "Casson Fluid Flow and Heat Transfer Over a Nonlinearly Stretching Surface,"Chin. Phys. B Vol. 22, No. 7 074701

http://dx.doi.org/ 10.1088/1674-1056/22/7/074701

Khalid Asma ,Iliyas Khan,Arshad Khan, and Sharidan Shafie, 2015, " Unsteady MHD Free Convection Flow of Casson Fluid Past Over an Oscillating Vertical Plate Embedded in Porous Medium." Engineering Science and Technology, an International Journal, 18(3), 309-317. http://dx.doi.org/10.1016/j.jestch.2014.12.006

Umamaheswar, M., Raju, M.C., Varma, S.V.K., 2015, "Analysis of MHD Transient Free Convection Flow of a Newtonian Fluid Past an Infinite Vertical Porous Plate," Frontiers in Heat and Mass Transfer (FHMT) 6, 18.

http://dx.doi.org/10.5098/hmt.6.18

Umamaheswar, M, Raju.M.C., and Varma,S.V.K, 2016, "MHD Convective Heat And Mass Transfer Flow of a Newtonian Fluid Past a Vertical Porous Plate With Chemical Reaction, Radiation Absorption and Thermal Diffusion," International Journal of Engineering Research in Africa, 19, 37-56.

http://dx.doi.org/10.4028/www.scientific.net/JERA.19.37

Hari R. Kataria , Harshad R Patel,(2016)" Soret and Heat Generation Effects on MHD Casson Fluid Flow Past an Oscillating Vertical Plate Embedded Through Porous Medium," 1110-0168 2016 Faculty of Engineering, Alexandria University Published by Elsevier B.V.

http://dx.doi.org/10.1016/j.aej.2016.06.024

Abiodun O. Ajibade, Ayuba M. Umar, 2015, "Effect of Chemical Reaction and Radiation Absorption on The Unsteady MHD Free Convection Couette Flow in a Vertical Channel Filled With Porous Materials," Afrika Matematika, 27(1), 201-213.

http://dx.doi.org/10.1007/s13370-015-0334-7

Seethamahalakshmi, .Ramana Reddy, G. V, and Prasad, B. D. C. N, 2011, "Effects of The Chemical Reaction and Radiation Absorption on an Unsteady MHD Convective Heat and Mass Transfer Flow Past a Semi-Infinite Vertical Moving in a Porous Medium With Heat Source and Suction," Vol. 1, Issue 1.028-036, IOSR Journal of Engineering.

Rassoulinejad-Mousavi, S.M., Yaghoobi, H., 2014, "Effect of NonLinear Drag Term on Viscous Dissipation in a Fluid Saturated Porous Medium Channel With Various Boundary Conditions at Walls," Arab $J$ Sci. Eng. 39(2), 1231-1240.

http://dx.doi.org/10.1007/s13369-013-0676-0

Seyed M. R. M., Saeid Abbasbandy, 2011, “Analysis of Forced Convection in a Circular Tube Filled With a Darcy-BrinkmanForchheimer Porous Medium Using Spectral Homotopy Analysis Method," Journal of Fluids Engineering, 133(10) ,101207-1.

http://dx.doi.org/10.1115/1.4004998 
Seyf, H.R., and Rassoulinejad-Mousavi, S.M., 2011, "An Analytical Study for Fluid Flow in Porous Media Imbedded inside a Channel with Moving or Stationary Walls Subjected to Injection/Suction," $J$. Fluids Eng., 133(9), 091203.

http://dx.doi.org/10.1115/1.4004822

Rassoulinejad-Mousavi, S.M., Seyf, H.R., Abbasbandy, S., 2013, "Heat Transfer Through a Porous Saturated Channel With Permeable Walls Using Two-Equation Energy Model," Journal of Porous Media 16 (3), 241-254.

http://dx.doi.org/10.1615/JPorMedia.v16.i3.60
Rassoulinejad-Mousavi, S.M., Abbasbandy, S., and Alsulami, H.H., 2014, "Analytical Flow Study of a Conducting Maxwell Fluid Through a Porous Saturated Channel at Various Wall Boundary Conditions," Eur. Phys. J. Plus, 129, 181,1-10

http://dx.doi.org/10.1140/epjp/i2014-14181-4

M. Umamaheswar, M. C. Raju, S.V.K. Varma., 2015, “Analysis of MHD transient free convection flow of a Newtonian fluid past an infinite vertical porous plate," Frontiers in Heat and Mass Transfer, 6 18 (2015).

http://dx.doi.org/10.5098/hmt.6.18 